\title{
Arsenic and amputations in Cambodia
}

\author{
James G. Gollogly, Adam C. Gascoigne, Colinda Holmes, Erin M. Kamp, Kayla Jenni, Say Bon Vath \\ Children's Surgical Center, Phnom Penh, Cambodia
}

\begin{abstract}
Background: Elevated levels of arsenic in drinking water in Cambodia were first identified in 1999. The first cases of suspected arsenicosis were identified by the WHO in 2002, and the first laboratory confirmed cases were found in 2006.

Objective: Present three patients with ulcerating tumors of the legs who came from two different districts in Cambodia.

Results: Cutaneous lesions characteristic of chronic arsenicosis were exhibited, and squamous cell carcinomas requiring amputation had developed. The clinical features of chronic arsenicosis and its surgical management were examined, in addition to its impact in Cambodia and current preventive strategies

Conclusion: There will be an increased incidence of these problems in the future. Medical practitioners in the Mekong River Basin should be aware of them, so as to recognize them early, and treat them appropriately.
\end{abstract}

Keywords: Amputation, arsenicosis, Cambodia, drinking water, squamous cell carcinoma

Arsenic has been known for a long time as a toxin. Due to the non-specific characteristics of acute arsenic poisoning, it has historically been employed as a means of assassination. Owing to the aristocracy's predilection for using it on one another, it earned the name of 'Poison of Kings'. In the modern era, arsenic has become the bane of a different level of society. By consumption of drinking water contaminated with arsenic, people of low socioeconomic status who reside in endemic areas suffer the consequences of a new syndrome: chronic arsenicosis.

Chronic arsenicosis was first recognized in the early twentieth century when long-term drinking of contaminated water caused toxicity in Argentina, Chile, Mexico, and Taiwan [1]. Skin lesions, multiple organ toxicity, and carcinogenesis, characterize the syndrome. A high incidence of arsenicosis is found in areas where arsenic contaminates the ground water which people drink. Cases have been reported in numerous countries around the world, especially in the Ganges and Mekong river basins, thus in India,

Correspondence to: Dr James G. Gollogly, MB, FACS, FRCSC, Children's Surgical Centre, PO Box 1060, Phnom Penh, Cambodia.E-mail: jim@csc.org
Bangladesh, Laos, Vietnam, Thailand, and Cambodia [2]. It is likely that arsenicosis, and other disorders resulting from chronic consumption of drinking water contaminated by toxins, will become more prevalent in the future, as expanding global populations face greater difficulties in the availability of water.

In this article, we present three cases which were treated at the Children's Surgical Centre in Phnom Penh in the last couple of years. A father and son both required amputations due to squamous cell carcinoma, contracted by consuming water from a well known to have high levels of arsenic, and a third patient who will most likely progress to an amputation, but who currently has had an attempt to save his leg through local excision of a similar cancer.

\section{Case presentation}

\section{Case 1 (Khu-16672)}

A 60 year old man from Preak Russei in Kandal province of Cambodia presented with a very large ulcer on the back of the left heel measuring about eight centimeters in diameter (Fig. 1).

Examination also revealed numerous hyperkeratotic papules on the palmar surface of the hands (Fig. 2), and on the thorax (Fig. 3). 


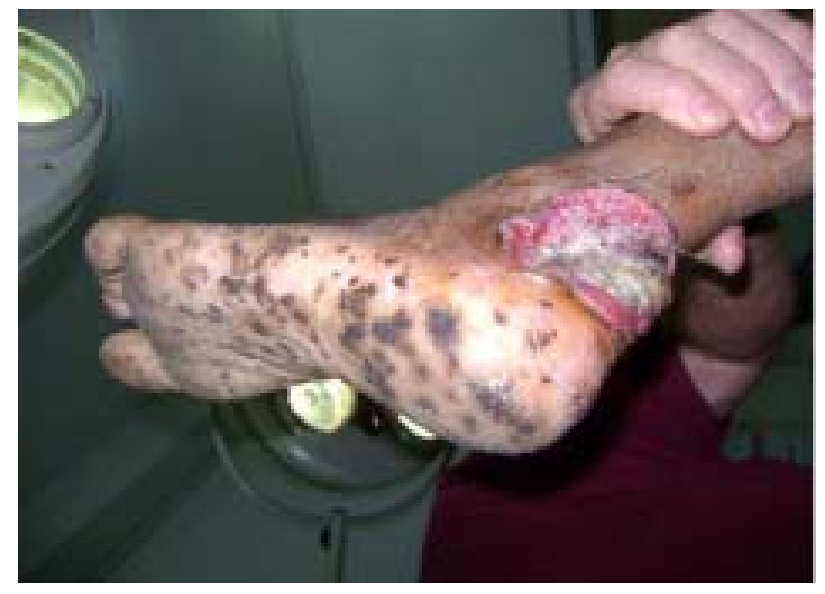

Fig. 1 Large ulcerating lesion on heel of left foot. Multiple hyperkeratotic and melanotic papules also visible on the plantar surface.

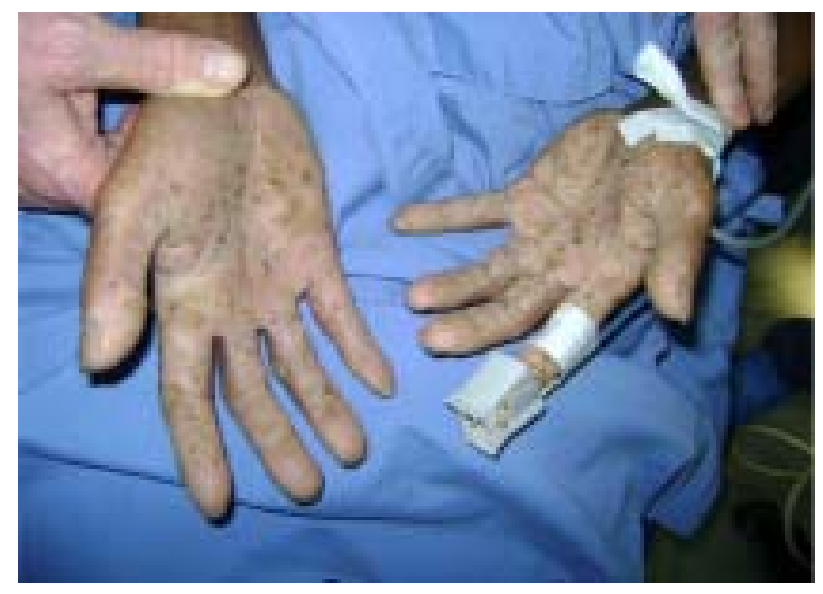

Fig. 2 Multiple hyperkeratotic and melanotic papules on palms of hands.

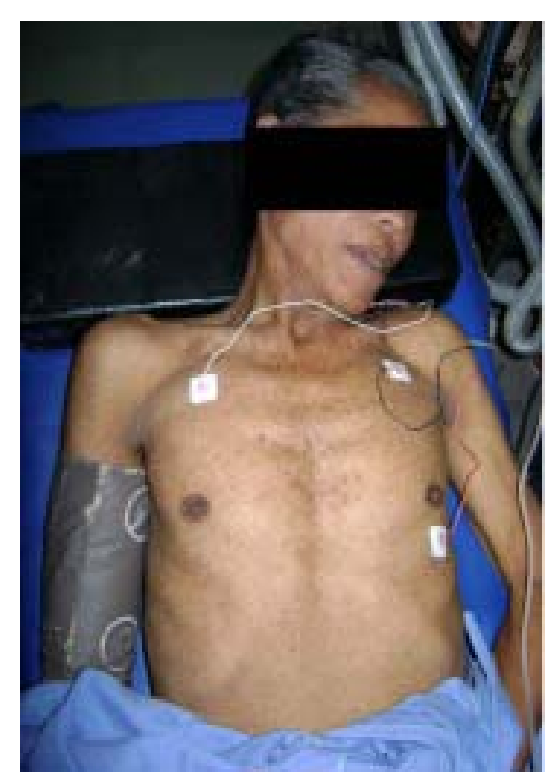

Fig. 3 Fine spots of melanosis on the trunk - 'rain drop pigmentation'.

The lesion on his ankle was excised and the defect covered with a split-thickness skin graft. Histopathological examination identified the tumor as an invasive squamous cell carcinoma. There was incomplete clearance of the cancer on the deep margin. It was decided that a below-knee amputation was a treatment that was more appropriate and the operation was subsequently performed under spinal anesthesia. The patient recovered uneventfully and was discharged. However, he returned again 18 months later with a swollen abdomen. The cause of the swelling was determined to be ascites. Ultrasonographic examination revealed an irregular, heterogeneous liver suggesting a diagnosis of liver cirrhosis. No treatment was available for the cirrhosis, so the patient was discharged, and we heard from his family that he died two months later.

\section{Case 2 (Chh-16673)}

A 25 year old male from the same village of Preak Russei, the son of the patient presented as Case 1, came later in May 2008 with a large cauliflower-shaped lesion on the sole of the right foot. He showed signs of chronic arsenic poisoning similar to his father, and a clinical diagnosis of squamous cell carcinoma was made. A Chopart amputation of the 
foot was performed under spinal anesthesia, and the lesion sent for histopathological examination, which confirmed the diagnosis. There was no overt evidence of metastatic disease. The tibio-talar-calcaneal arthrodesis healed uneventfully (Fig. 4), and the stump functioned well for weight bearing (Fig. 5).

The patient was followed up during a visit to his home in Preak Russei village 18 months later. He was found to be severely ill, with cachexia, anorexia, and a large ulcerating lesion on his right upper thigh (Fig. 6).

He was readmitted to the Children's Surgical Centre, where a clinical diagnosis was made of squamous cell carcinoma metastatic to the lymph nodes in the groin. His weight had dropped to $34 \mathrm{~kg}$, but he refused all further treatment, and demanded to be allowed to return home to die, so his wishes were honored. Within a month, his family informed us that he had indeed died.
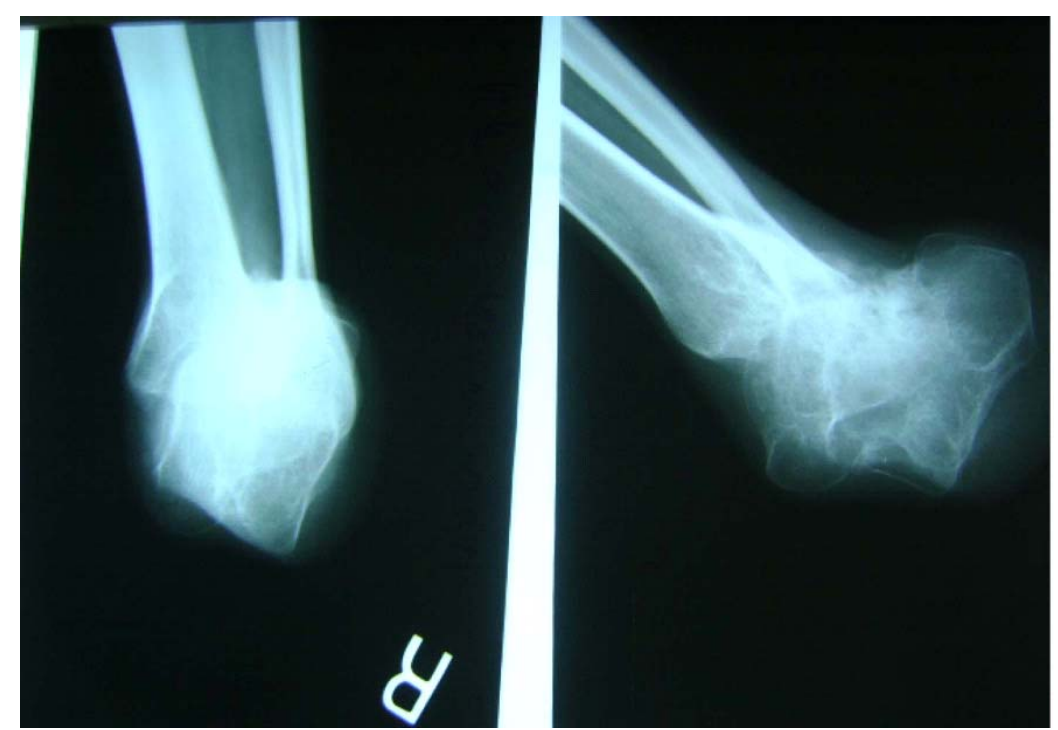

Fig. 4 Well-healed tibio-talar-calcaneal fusion.

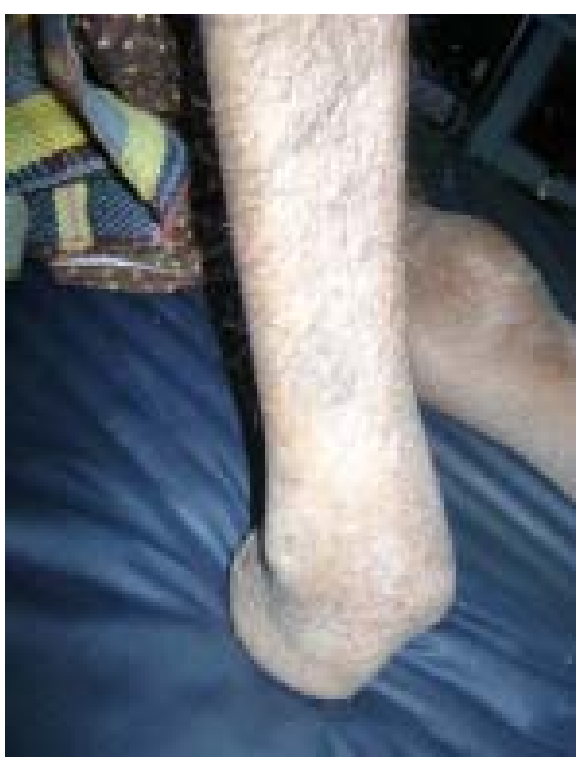

Fig. 5 Weight bearing Chopart stump. 


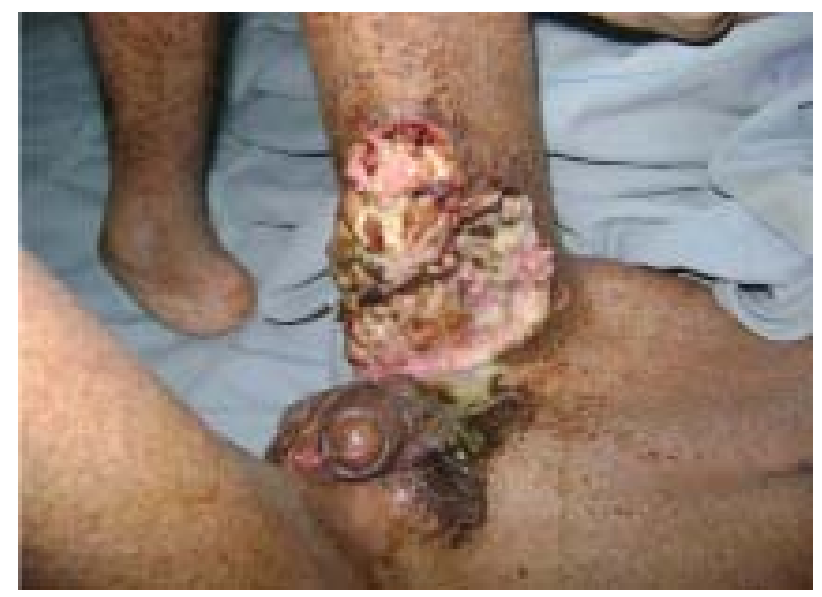

Fig. 6 Lymphatic metastases in the groin.

\section{Case 3 (Pin-18893)}

A 38 year old male, from an adjoining province, Prey Veng, presented with similar signs in early 2010, and with a large tumor on the lateral aspect of his right ankle (Fig. 7).

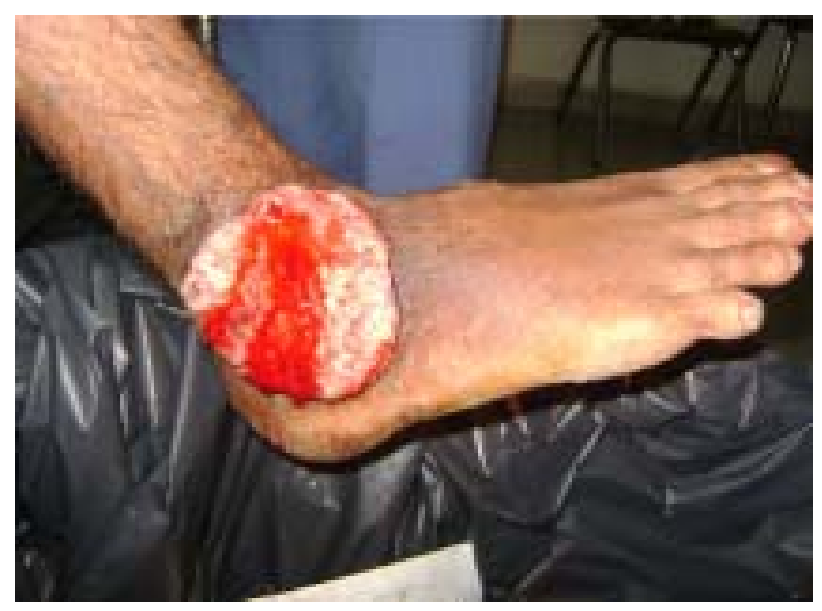

Fig. 7 Large carcinoma on lateral ankle.

He knew he had chronic arsenicosis, but refused to have an amputation, so the tumor was excised together with the lateral malleolus, which had clinically been invaded. The ankle was fused (Fig. 8), and a skin flap was rotated from the back of his leg to cover the defect.

The histology report again diagnosed Squamous cell carcinoma. No evidence of metastatic disease can be currently found, but it is likely that this man will have a recurrence, or even a new tumor, and will subsequently need an amputation, if he does not die beforehand from other effects of arsenic poisoning.

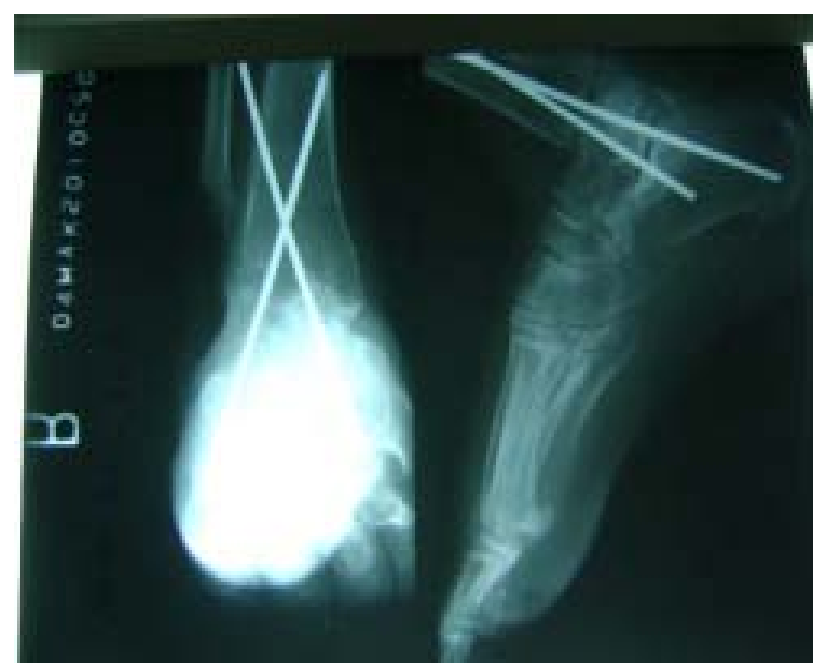

Fig. 8 Excision of lateral malleolus and fusion of ankle.

\section{Discussion}

These cases demonstrate the potential complications of arsenicosis such as squamous cell carcinoma, metastases, organ failure, and death. Two of the patients in this report are first-degree relatives from Preak Russei, which is the village where the first Cambodian cases of chronic arsenicosis were identified [2]. The inhabitants, for more than ten years, had consumed water from a tube well that the Ministry of Rural Development had drilled to help them have a convenient water supply. Testing for arsenic in the water was not done until 2006. More than 200 inhabitants have so far been found to have skin markers indicative of arsenicosis, and about 10 patients are known to have developed cancers, of whom two are reported to have died. Our two patients report that they have another close family member with a large ulcer on his leg, most likely another skin cancer. Our third patient reports that his village in Prey Veng, paid a private contractor to dig a well for the village in 2000, which was not tested for arsenic until 2006. It resulted in at least 20 people in his village with signs of arsenicosis by the time the people were told the well water was contaminated.

Arsenicosis is characterized by distinctive cutaneous lesions, multiple organ system toxicity, and carcinogenesis due to long-term arsenic consumption. It was defined by the WHO working group as a "chronic health condition arising from prolonged ingestion (not less than six months) of arsenic above a safe dose, usually manifested by characteristic skin lesions, with or without involvement of internal 
organs" [3]. Cutaneous lesions include hyperkeratoses, melanosis, rain-drop pigmentation, leucomelanosis, and skin cancers. Arsenicosis also causes atherosclerosis, hepatotoxicity, peripheral neuropathy, respiratory symptoms, blood dyscrasias and possibly an increased incidence of diabetes mellitus [1]. Further, in addition to skin cancer, arsenicosis is associated with cancers of the lung, bladder, kidney, prostate, liver, uterus, and lymphatic tissues [1]. The cutaneous lesions are not pathognomonic of arsenicosis, but they are distinctive enough to arouse a high level of suspicion in patients who reside in endemic areas. If possible, clinically suspected cases should be confirmed by sending hair and nail specimens, in addition to a sample of drinking water, to a laboratory for testing of arsenic concentration. Alternatively, field test kits may be used to test wells on site. The currently acceptable limit for arsenic concentration in drinking water is set at 0.01 grams per liter, but the limit set by the Cambodian government is 0.05 grams per liter [4]. Prevention of arsenicosis requires intermittent testing of groundwater sources, community involvement, and education about the causes and symptoms of arsenicosis. Wells which are found to be contaminated should be replaced with an alternative water source such as surfacewater, rainwater, or water from a shallow dug well.

There is currently no effective treatment for established arsenicosis. Use of chelating agents such as dimercaptosuccinic acid (DMSA) and dimercaptopropene succinate (DMPS) have had mixed results in trials, but they may offer some hope in a primary treatment of chronic arsenicosis. Hyperkeratinisation may be treated with topical therapies such as salicylic acid or retinoids. Dyspepsia may be treated with $\mathrm{H}_{2}$-receptor blockers. Calciumchannel blockers may be effective in ameliorating ischaemic pain by relieving vasospasm. Beyond these limited treatments, the only effective therapy is removal of the source of arsenic, and provision of a safe alternative supply of drinking water [5].

In the majority of cases of severe arsenicosis, a major cause of morbidity and mortality is squamous cell carcinoma (SCC), which is a malignant tumor arising from epidermal keratinocytes. Premalignant actinic keratoses and in situ SCCs may be treated using topical therapies, but to minimize the chance of metastasis, the goal of treatment of an established SCC is complete excision.

In Cambodia, elevated levels of Arsenic were discovered in 1999 by the Cambodian Government's
Ministry of Rural Development during the national drinking water quality survey, sponsored by the World Health Organization (WHO). This led to the formation of the Arsenic Inter-Ministerial Subcommitee in 2001. It decided to adopt the maximum safe arsenic concentration then held by the WHO $(50 \mathrm{mcg} / \mathrm{L})$. In 2002, several NGOs were given the task of investigating wells for arsenic contamination, and educating the community about safe drinking water and arsenicosis. However, this effort was poorly followed up and drilling of new wells was permitted in arsenic-contaminated areas without requiring testing before use. A health assessment carried out by WHO and UNICEF in that year, 2002, also found the first suspected cases of arsenicosis in Cambodia. In 2003, an intensive well-testing effort was started and involved several organisations, including the Ministry of Health and Resource Development International-Cambodia (RDI-C). It found $29 \%$ of wells tested to have arsenic concentrations above the permissible limit. In 2006, the first confirmed cases of arsenicosis in Cambodia were identified in Preak Russei [4]. Following an intensive campaign by RDI-C and the Ministry of Health, villagers ceased using well water for drinking. Instead, they used boiled river water. Arseniccontaminated tube well water is aesthetically less pleasing in taste, color, and smell than uncontaminated water, causing those people who drink it to seek alternatives even without knowledge of its arsenic content. However, some of the poorest people are forced to drink from a well that they know to be contaminated, as there is no other acceptable supply.

No generalized clinical screening program for arsenicosis yet exists in Cambodia, and the Cambodian Ministry of Health does not collect statistics on its incidence. Without such information, it is impossible to know the true incidence of arsenicosis in Cambodia, but as arsenic is known to be present in much of the Lower Mekong Basin, many villagers will likely be affected (Fig. 9).

\section{Conclusion}

Elevated levels of arsenic exist in groundwater sources around the Mekong and Tonle Bassac rivers in Cambodia. In specific communities of low socioeconomic status, chronic consumption of arsenic results in a characteristic syndrome of melanosis and keratosis, organ toxicity, and carcinogenesis. A major cause of morbidity and mortality among arsenicosis sufferers is squamous cell carcinoma (SCC). The 


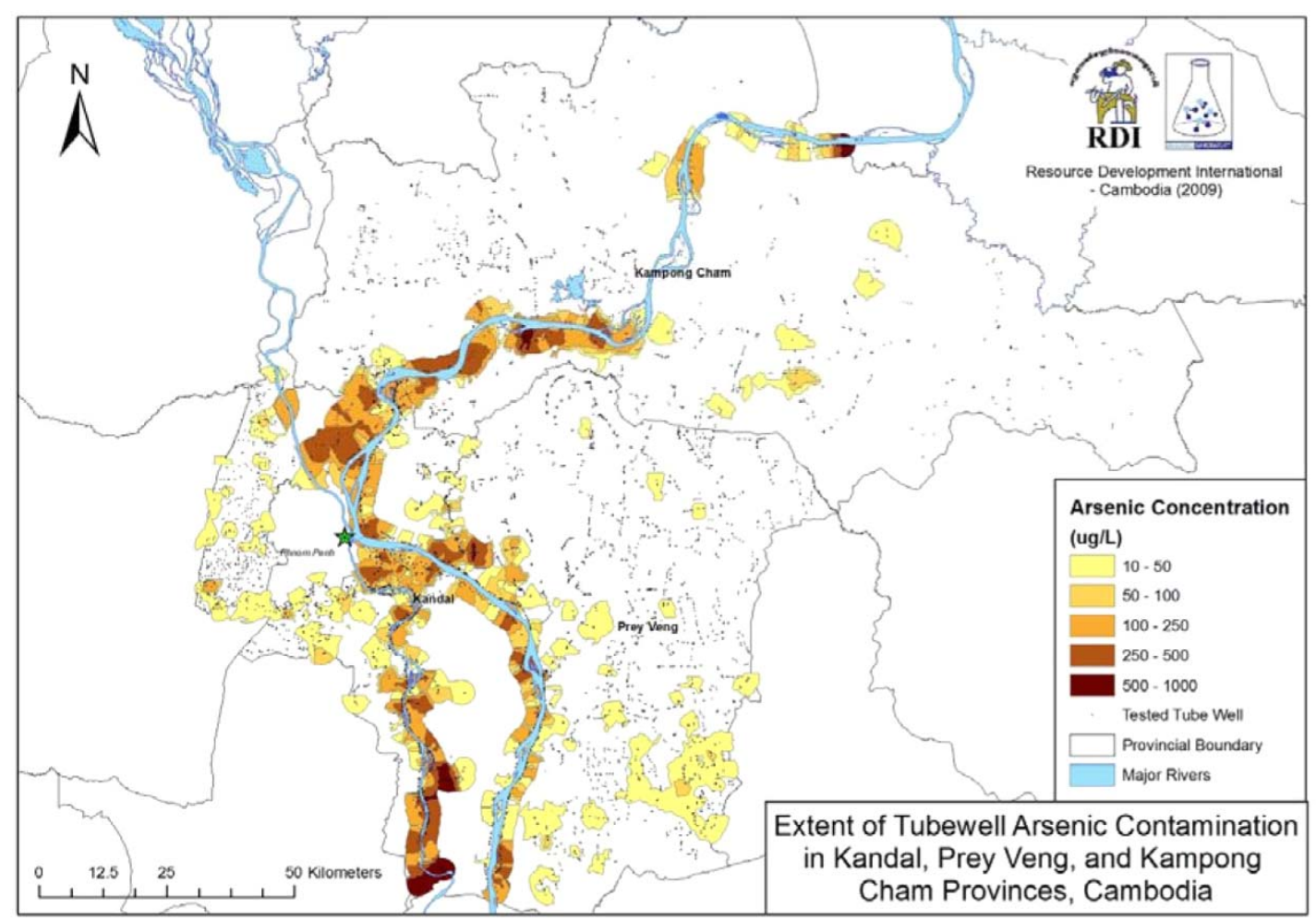

Fig. 9 Map of the central provinces of Cambodia illustrating arsenicosis risk along the Mekong and Tonle Bassac rivers. (Image courtesy of Resource Development International-Cambodia).

mainstay of treatment of SCCs in a resource-poor setting is surgery. Tackling a problem such as chronic arsenicosis requires adopting a population health perspective. Only through routine testing of groundwater and mapping of contaminated locations can problem areas be identified and effective interventions employed. Then, villagers can be educated about the problem of arsenicosis, and instructed not to use tube wells for drinking water. However, they have been poisoned for many years; the final reckoning will be still to come.

\section{Acknowledgements}

The authors would like to thank Mr. Andrew Shantz and the other staff at Resource Development International-Cambodia for generously offering their time and assistance. They have no conflict of interest to declare.

\section{References}

1. Sengupta SR, Das NK, Datta PK. Pathogenesis, clinical features and pathology of chronic arsenicosis. Indian J Dermatol Venereol Leprol. 2008; 74:559-70.

2. Mazumder DN, Majumdar KK, Santra SC, Kol H, Vicheth C. Occurrence of arsenicosis in a rural village of Cambodia. J Environ Sci Health (Pt A). 2009; 44: 480-7.

3. Arsenicosis Case-Detection, Management and Surveillance. Report of a Regional Consultation. New Delhi:WHO Regional Office for South-East Asia, 2003.

4. Sampson ML, Bostick B, Chiew H, Hagan JM, Shantz A. Arsenicosis in Cambodia: case studies and policy response. Appl Geochem. 2008; 23:2977-86.

5. Das NK, Sengupta SR. Arsenicosis: diagnosis and treatment. Indian J Dermatol Venereol Leprol. 2008; 74:571-81. 